\title{
Discussion on Water Vapor Source Based on Hysplit Model and Characteristics of the Isotopes in Precipitation in Yinchuan
}

\author{
Xie Fei ${ }^{1,2 a *}$, Yu Yan-ling 2 , Qin Xiang-nan² \\ ${ }^{1}$ Pingliang Monitoring Sub-station of Soil and Water Conservation, Pingliang 744000, China \\ ${ }^{2}$ College of Water Conservancy and Hydropower Engineering, Hohai University, Nanjing 210098, \\ China \\ a18252502@qq.com
}

Keywords: Environmental Isotopes; Precipitation; Backwards Trajectory; Temperature effect

Abstract. Base on Hysplit model with Backwards Trajectory showed Yinchuan was dominated by westerly continental vapor throughout the year, and also was influenced by the maritime vapor in spring and summer. Owing to the high temperature, Yinchuan was remarkably effected by local evaporation of water vapor in spring and summer. By dint of isotopes data of the meteoric precipitation in Global Network of Isotopes of Yinchuan station, the changes characteristics of precipitation in Yinchuan were analyzed. The analysis of the relationship between $\delta 180$ with precipitation and temperature respectively implied that the weighted average of $\delta 180$ took on a good "temperature effect". At the same time, it showed a positive correlation between the weighted average of $\delta 180$ and precipitation, which was related to the arid and semi-arid climate of Yinchuan. The slope and intercept of local meteorological water line (LMWL) of Yinchuan were lower than that of Global Meteorological Water Line ( GMWL) and Chinese precipitation line.

\section{Introduction}

The application of environmental isotopes $\left({ }^{18} \mathrm{O},{ }^{2} \mathrm{H}\right)$ method is valuable to the study of water environment and isotopes hydrology ${ }^{[1]}$, and its application in the research of precipitation began in the early $1950 \mathrm{~s}{ }^{[2]}$. Researches have shown that stable isotopes composition in precipitation and their value depends on the initial state of the source area and the transport process of water vapor ${ }^{[3]}$, and differs from other factors of the study area, such as the temperature, humidity, altitude, latitude and longitude etc. In 1961, the International Atomic Energy Agency (IAEA) and the World Meteorological Organization (WMO) jointly initiated and established the Global Network of Isotopes in Precipitation (GNIP), in order to provide the basic data to determine the global or regional water cycle mechanism. Since the 1970s, many researches on stable isotopes composition of regional or basin precipitation have been done, and various environmental effect of precipitation isotopes have been analyzed ,to study area or river basin water cycle characteristics ${ }^{[4]}$.

According to the important research progress of the study on water vapor source, transmission process and mechanism in China's northwestern region, some typical small regions have their unique water vapor transport process which is different from the whole northwest of large area, for the complexity of and uniqueness the water cycle of this region. Due to the lack of observation data, the traditional pattern of water vapor transport process research is limited to some extent, but it shows great superiority to apply the environmental isotopes technology combined with meteoric circulation patterns for water vapor transport process research. Salatid studied the regional water circulation of the Amazon basin and the contribution of local water resources with ${ }^{18} \mathrm{O}{ }^{[5]}$. This paper utilized the hydrogen and oxygen isotopes data and the water vapor path data from the backward trajectory method of Yinchuan, the hinterland of northwest China, to make a qualitative evaluation of contribution of precipitation by 
different source of water vapor, which can provide scientific basis to understand and grasp the regional hydrologic cycle process and protect and utilize the water resources reasonably.

\section{Engineering Background}

Yinchuan area located in the hinterland of China's inland, the scope of its geographic coordinates to $37^{\circ} 29^{\prime} \sim 38^{\circ} 53^{\prime} \mathrm{N}, 105^{\circ} 49^{\prime} \sim 106^{\circ} 53^{\prime} \mathrm{E}$. The terrain is divided into mountains and plains, southwest is high and north east is low, and its average altitude is 1010 1150 m. The Helan Mountain, which locates in west and strikes towards the north by east ,about $150 \mathrm{~km}$ long, with a maximum altitude of $3556 \mathrm{~m}$, is the natural barrier resisting the northwest cold air into Yinchuan. Yinchuan belongs to the temperate arid climate zone, with typical continental climate characteristics, whose winter is long and cold and summer is short and sunny. Its Years of average rainfall is $183.59 \mathrm{~mm}$, mainly concentrated in 6 - in September, and the average annual evaporation is $1662.33 \mathrm{~mm}$.

The data of Yinchuan Precipitation isotopes $\delta \mathrm{D}$ and $\delta 180$ isotopes data is referred from the Global Network of Isotopes in Precipitation (GNIP). The Yinchuan station is $106.22^{\circ} \mathrm{E}, 38.48^{\circ} \mathrm{N}$, and the monitoring times were $1988 \sim 1992,1999 \sim 2000$, with some months missed. Each observation point in the network project including items such as the $\delta \mathrm{D}, \delta^{18} \mathrm{O},{ }^{3} \mathrm{H}$, temperature and precipitation, and the data recording time was 15 th of every month, so the stable isotopes ratio of months can represent the average, from the 16th last month to the 15 th of this month.

$\delta^{18} \mathrm{O}_{\mathrm{i}}$ represents monthly stable isotope's ratio and $\mathrm{P}_{\mathrm{i}}$ is corresponding precipitation. Weighted monthly average values of isotopes in precipitation for Yinchuan showed in Table 1.

Table 1 Weighted monthly average values of isotopes in precipitation for Yinchuan

\begin{tabular}{cccc}
\hline Mouth & $\delta \mathrm{D} / \% 0$ & $\delta^{18} \mathrm{O} / \% 0$ & Precipitation $/ \mathrm{mm}$ \\
\hline Jan & -111.50 & -15.70 & 2.00 \\
Feb & -95.36 & -13.98 & 3.71 \\
Mar & -44.36 & -7.48 & 7.43 \\
Apr & -34.20 & -6.14 & 15.32 \\
May & -13.72 & -3.37 & 29.39 \\
Jun & -19.24 & -3.93 & 18.44 \\
Jul & -62.58 & -8.91 & 40.73 \\
Aug & -45.06 & -6.00 & 45.41 \\
Sep & -49.61 & -7.68 & 25.57 \\
Oct & -67.58 & -10.53 & 9.79 \\
Nov & & & 1.87 \\
Dce & -147.70 & -19.97 & 1.22 \\
\hline
\end{tabular}

In order to verify the water vapor source situation of Yinchuan, Hysplit Model is applied in this paper, combined with the global reanalysis data from 1999 to 2001 of Air Resources that the National Oceanic and Meteoric Administration, to establish the Backwards Trajectory Model of the source of water vapor of Yinchuan in 2000.Main selected parameters are as blow: Direction: Back; Total run time: -318h; Top of model (m agl): 10000.0; Height (m-AGl): 100, 500,1000; Vertical Motion Method: 0

\section{Water vapor sources and its relationship with the $\delta 180$}

The value of $\delta^{18} \mathrm{O}$ is low in autumn and winter, and the water vapor sources are mainly the Atlantic Ocean, the Mediterranean Sea and the Arctic Ocean, according to the Backwards Trajectory (Figure 1. a, d). The vapor flow, containing water, from the Atlantic ocean and the Mediterranean, went through the Middle East, central Asia, then northern Xinjiang Region, and into the China's northwest area, and arrived in Yinchuan finally. The precipitation cloud went along the Ural Mountains to the south from 
the Arctic Ocean into central Asia, then along the Silk Road towards east to Yinchuan. Water vapor of the westerlies dominated in this period, and the water vapor transport over long distance resulted in the dilution of stable isotopes in water vapor. Precipitation in fall and winter rainfall was less mainly because of the poor condition of the water vapor of the westerlies.

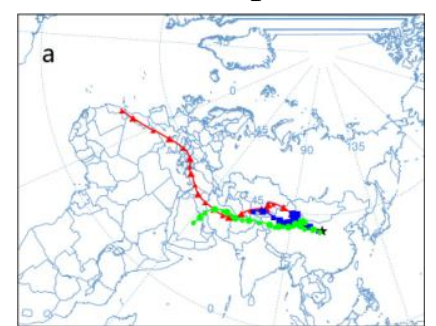

(a)Winter

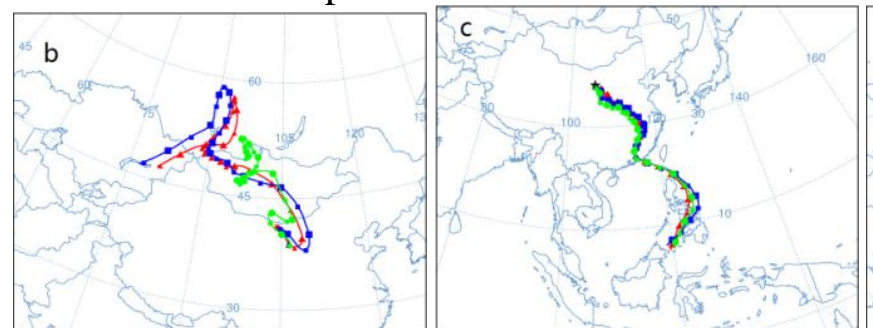

(b) Spring (c) Summer

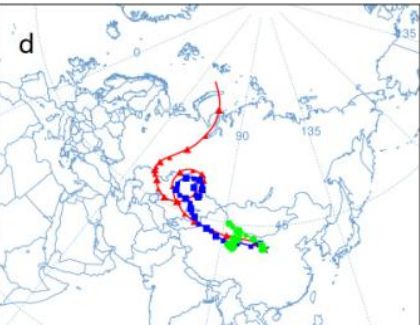

(d)Autumn

Figure. 1 The trajectory of water vapor in different seasons

The value of $\delta^{18} \mathrm{O}$ was relatively high in spring and summer, comparing with in fall and winter. Affected by marine water vapor, Rainfall increased in this period. Rain water vapor mainly came from the low latitudes and the Pacific Ocean, carried by the East Asian monsoon (Figure 1. b, c); due to the Himalayan block, it is difficult for southwest monsoon to reach the northwest inland. Even with a small amount of southwest monsoon water vapor into Yinchuan, its impact is relatively small because the $\delta^{18} \mathrm{O}$ in precipitation was washed fiercely and decreased sharply when the water vapor climbed over the Himalayas and the Tibet Plateau, with the average altitude of more than $4000 \mathrm{~m}$. Water vapor of Yinchuan in spring is still the westerlies continental water vapor mainly, dominated by water vapor from Kazakhstan, Mongolia Plateau and other Asian northern areas. Due to the enrichment of heavy isotopes of continental moisture, combined with local secondary evaporation making the $\delta 1^{8} \mathrm{O}$ value higher, the final value of $\delta^{18} \mathrm{O}$ of meteoric precipitation was on the high side.

\section{Season scale change of $\delta 180$ of precipitation}

The weighted monthly average of $\delta^{18} \mathrm{O}$ in Yinchuan precipitation showed a strong seasonal change rule: it was high in spring and summer and low in autumn and winter, which is consistent with the seasonal variation law of temperature (Figure 2. a). The maximum difference value of $\delta^{18} \mathrm{O}$ in summer and winter reached $15.61 \%$, the reason may be: 1) the summer temperature is higher, which had certain effect on $\delta^{18} \mathrm{O}$ in precipitation, and the low temperature in autumn and winter led to isotopes dilution in precipitation; 2) the precipitation in autumn and winter was more solid, under the condition of low temperature, the whole precipitation process was less susceptible to be influenced by secondary evaporation and the meteoric water vapor exchange, but the influence of secondary evaporation and dynamic fractionation effect cannot be underestimated in spring and summer.

The relationship between the $\delta \mathrm{D}$ and $\delta^{18} \mathrm{O}$ in meteoric precipitation is of great significance to the study of the change of stable isotopes in the process of water circulation. According to the data of $\delta \mathrm{D}$ and $\delta^{18} \mathrm{O}$ in Yinchuan of long time series, the meteoric precipitation line equation of Yinchuan was acquired by the least square method, shown in equation (1).

$$
\delta D=7.92 \delta^{18} O+4.24\left(R^{2}=0.97\right)
$$




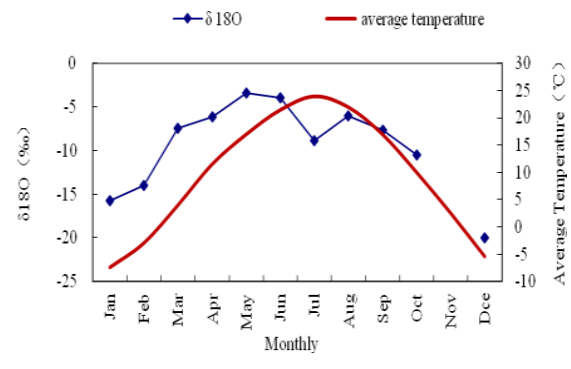

(a) Temperature

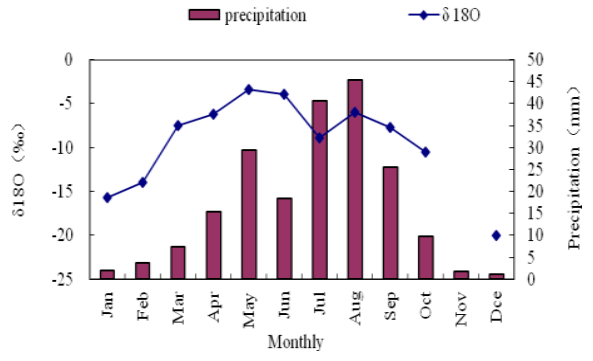

(b) precipitation

Figure. 2 The correlation of $\delta 180$ with monthly average temperature and precipitation

\section{Conclusions}

(1) Located in the northwestern region of China, Yinchuan is mainly controlled by the westerlies activities, which is the consistent with some scholars' research ${ }^{[16]}$. In autumn and winter, the influence of westerlies continental local water vapor sources is higher; the westerlies continental water vapor is still principal in spring and summer, under the influence of oceanic water vapor at the same time. Due to the higher temperature, local evaporation of water vapor is quite obvious.

(2) The weighted monthly average of $\delta^{18} \mathrm{O}$ in Yinchuan precipitation showed a strong temperature effect, the reason may be that the whole precipitation process was less susceptible to be influenced by secondary evaporation and the meteoric water vapor exchange, for the low temperature in autumn and winter, but the precipitation is likely to be influenced by secondary evaporation and dynamic fractionation effect under the higher temperature in spring and summer.

(3) The local meteoric precipitation line equation of Yinchuan is $\delta D=7.92 \delta^{18} O+4.24$ and its slope and intercept are low, compared with the Global Meteoric Water Line (GMWL) and China's Meteoric Water Line, which has a certain relationship with the arid climate of Yinchuan. In arid regions, $\delta^{18} \mathrm{O}$ and $\delta \mathrm{D}$ in surface water is on the high side, so the $\delta^{18} \mathrm{O}$ and $\delta \mathrm{D}$ in evaporated water vapor is also on the high side; at the same time, due to the heavy isotopes enrichment made by evaporation, $\delta^{18} \mathrm{O}$ in precipitation in spring and summer of Yinchuan is high.

\section{References}

[1] Dansgaard W. The abundance of 180 in atmosphere water and water vapor [J]. Tellus, 1953, 5: 461-469.

[2]Clark I D, Fritz P. Environmental Isotopes in Hydrogeology [M]. Boca Raton, FL: Lewis Publishers, 1997: 328.

[3] Rozanski K, Araguas L, Gonfiantini R, Relation between long-term trends of oxygen-18 isotope composition of precipitation and climate [J]. Science, 1992, 258: 981 -985.

[4]Tian Lide, Yao Tandong, Pu Jianchen, Yang Zhihong. Characteristics of $\delta 180$ in Summer Precipitation at Lhasa[J]. Journal of Glaciology and Geocryology, 1997, 19( 4) : 295 -301.

[5] Salati E., Dall Olio A, Matsui E., Recycling of water in the Amazon basin; an isotopic study [J]. Water Resources Research, 1979, 15(5):1250 -1258. 